\title{
Trascendencia e inmanencia del Intelecto. Los casos de Anaxágoras y Giordano Bruno
}

The transcendence and immanence of the Intellect. The cases of Anaxagoras and Giordano Bruno

Diana María Murguía

Monsalvo

Universidad de Navarra

Departamento de Filosofía

Facultad de Filosofía y Letras

31009 Pamplona (España)

diana.murguiam@gmail.com

Abstract: The article presents and compares the perspectives of Anaxagoras and Giordano Bruno on the intellect as an efficient cause of the world. It is shown that while both concepts indicate the transcendence and the immanence of the intellect, neither manages to establish either transcendence or immanence in a categorical manner. This ambivalence shows that the intelligent cause of the world is detectable in nature because of its actions, but not because of its being.

Keywords: Anaxagoras, Giordano Bruno, intelligent cause, immanence.
Resumen: El artículo presenta y relaciona los planteamientos de Anaxágoras y de Giordano Bruno acerca de un intelecto comprendido como la causa eficiente del mundo. Se muestra que ambas concepciones indican ya la trascendencia, ya la inmanencia del intelecto; sin embargo, ninguna termina por afirmar su ser trascendente o inmanente de manera categórica. Esta ambivalencia compartida pone de manifiesto que la causa inteligente es perceptible en la naturaleza por su acción, pero no por su ser.

Palabras clave: Anaxágoras, Giordano Bruno, intelecto universal, inmanencia. 
n el ámbito filosófico, la concepción de que el universo posee una causa inteligente que lo ordena se encuentra presente desde los planteamientos de los presocráticos. Se halla de manera implícita en el arjé universalmente activo de los milesios ${ }^{1} \mathrm{y}$ se descubre con mayor perfilación —aun inmerso en la 'oscuridad' de su autor- en el lógos heraclíteo, esa Razón que marca las medidas del cambio al fuego cósmico. Sin embargo, es Anaxágoras quien concretiza, determina y nombra a esta causa como 'nous', lo que le valió ser reconocido por los pilares de la filosofía griega clásica²

Es posible considerar que el paso especulativo de Anaxágoras es haber hecho explícita esa inteligencia configuradora que estaba implícita o contenida en el principio material de los milesios. Exteriorizando esa inteligencia propia del arjé de los jonios, habría 'extraído' a la inteligencia del principio material, es decir, la habría separado de la materia. Por eso se dice que la filosofía de Anaxágoras es 'dualista', pues se comprende que el nous y la materia son principios igualmente co-eternos. Será ésta la puerta de entrada a nuestro tema: ¿en qué 'grado' o 'medida' (si se me permite el término) puede hablarse de la separación del nous con respecto a la materia en la propuesta de Anaxágoras? Si bien existe una 'separación', es decir, características que hacen comprender al nous trascendente, se observa también que esa desvinculación material no termina de ser radical. Hay pues, indicios de su inmanencia y materialidad.

Abordaré esta temática recordando al lector la 'parcialidad' que conlleva implícito todo trabajo con los fragmentos de la sabiduría

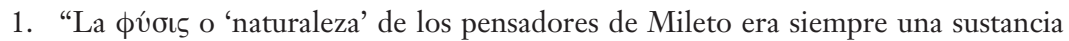
extensa, esto es, material, pero su idea no se agotaba con este predicado: ella era, simultánea e indiferenciadamente, principio de movimiento y de inteligencia cósmica. La sustancia originaria y universal aparece así como una realidad viviente [semoviente] y aun inteligente. Materia, vida y espíritu estaban identificados o, por mejor decir, no distinguidos en la unidad originaria”. A. CAPpellett, La filosofía de Anaxágoras. (Sociedad Venezolana de Filosofía, Caracas, 1984) 243.

2. Como se sabe, el hecho de haber introducido al nous en la explicación del universo es la razón por la cual Anaxágoras es elogiado pero también criticado por Platón y Aristóteles: Cfr. Platón, Fedón 97c y ss., y ARIstóteles, Metafísica I 984b 13-18; y 985 a 18-21.

3. Comprendido así desde Aristóteles. Cfr. Aristóteles, Metafísica, I, 8, 989 a 3032. 
presocrática, que, lejos de un contratiempo, nos pone frente a la evidencia de lo "incompleto" que implica toda aventura filosófica.

Lo relacionaré con el planteamiento del renacentista Giordano Bruno, quien, bajo su herencia neoplatónica pero con su propia adopción, concibe un intelecto como la causa eficiente del todo. Este intelecto es por quien el universo, que es infinito para Bruno, es formado en cada una de sus partes y elementos, es decir, lo configura en totalidad y en perennidad. Lo propio de este agente es que su función la realiza desde el interior de la materia y en unidad con ella. Dicho esto, podría afirmarse sin más la inmanencia bruniana porque concibe a la causa inteligente del universo inmersa en la materia del mismo. Sin embargo, Bruno afirma a la vez su trascendencia ontológica.

Como puede vislumbrarse, la independencia material del intelecto es ambivalente en ambos casos, ya sea si se subraya su trascendencia, como parece que hace Anaxágoras, o bien la inmanencia, como Bruno. No obstante, en ninguna de las dos perspectivas puede afirmarse una u otra 'cualidad' de modo categórico.

La relación que estableceré entre estos dos autores no es fortuita. Bruno asimila en su filosofía las tesis de los presocráticos y comparte con ellos esa visión naturalista universal, volviendo a sus concepciones y renovándolas bajo un matiz propio. Puede, por ejemplo, observarse de modo presto que la concepción bruniana de la inteligencia universal inmersa en la materia es de algún modo ese retorno a los inicios de la filosofía jonia y el monismo natural. En el caso de la relación con Anaxágoras, veremos que pareciendo que están ambos en las antípodas al respecto de favorecer la trascendencia o la inmanencia del intelecto, sus posturas plantean una similitud. Lo que incluso, a la luz de los estudios brunianos, permite reconocer al nous como antecedente del intelecto universal del filósofo renacentista ${ }^{4}$.

4. La relación del intelecto bruniano con el nous de Anaxágoras aún ha sido poco explorada. Los estudios precedentes de esta temática son: R. MEndoza, Precursores del concepto bruniano de intellectus universalis en la antica filosofía, en L. BENÍTEZ, J. A. Robles (eds.), Giordano Bruno 1600-2000. (UNAM, México, 2002) 9-27; A. N. Zoumpos, Zwei anaxagoreische Punkte in der Lebre von Giordano Bruno, "Platon" 18 (1966) 214. 


\section{LA TRASCENDENCIA DEL INTELECTO: EL CASO DE ANAXÁGORAS}

Anaxágoras concibe una cosmogonía donde todas las cosas (preexistentes) constituían una mezcla material: "Juntas estaban todas las cosas, infinitas en número y pequeñez [...]" . A causa de la pequeñez y de la mezcla no podían percibirse ni distinguirse unas de otras. Este estado originario se caracterizaba por ser estático, pues el cosmos, tal y como lo conocemos, nació a partir del movimiento.

$\mathrm{El}$ agente que inicia el movimiento es el nous. Origina una rotación que se extiende paulatinamente sobre zonas más amplias de la mezcla, generando con ello la separación de las cosas que estaban en combinación. El intelecto "[...] controló la rotación universal e hizo que todo girara en el principio" y al hacerlo, "[...] todo cuanto la Mente movió quedó separado; mientras las cosas se movían y eran divididas, la rotación aumentaba grandemente su proceso de división"7.

Aún con el ímpetu del movimiento, la separación que desencadena el impulso rotatorio no ocurre de manera anárquica o desordenada. Controlado por el nous, el movimiento provoca la reunión de las cosas en porciones, cada contrario se separa de su opuesto: "Lo denso se separa de lo raro, lo cálido de lo frío, lo brillante de lo tenebroso y lo seco de lo húmedo" ", aunque —esto es importante- no se separan de manera radical. A pesar de la división que provoca el nous, ninguna cosa se separa totalmente de las otras, sino que "todas tienen una porción de todo" ". El movimiento del nous no desliga a las cosas ni a los contrarios entre sí de manera absoluta: "no están separadas unas de otras las cosas del cosmos ni cortadas con un hacha, ni lo caliente de lo frío, ni lo frío de lo caliente" ${ }^{10}$.

5. DK 59 B 1. Para los fragmentos de Anaxágoras: H. A. Diels, W. KranZ, Die Fragmente Vorsokratiker (Weidmannsche Verlagsbuchhandlung, Berlin, 1960). Para la traducción en castellano uso las versiones de: G. S., KiRK, J. E., RAVEN, M. SCHOFIELD, Los filósofos presocráticos. Historia crítica con selección de textos, Trad. Jesús García Fernández (Gredos, Madrid, 2008) y W. K. C. GuTHrIE, Historia de la filosofía griega, Trad. Alberto Medina González, Tomo II (Gredos, Madrid, 1986).

6. DK 59 B 12 .

7. DK 59 B 13.

8. DK 59 B 12.

9. DK 59 B 6.

10. DK 59 B 8. 
Anaxágoras — atendiendo la crítica parmenídea- busca señalar que las cosas no surgen de la nada ni dejan de ser, ya que todo existía desde la mezcla originaria. $Y$, posterior a la rotación iniciada por el nous todo sigue existiendo en todo, incluso en sus contrarios. En este contexto cada cosa es y se distingue del resto por aquello que tiene en mayor proporción ${ }^{11}$. El cambio y la alteración se explican por una reordenación de las partes y la generación y la destrucción no son sino la unión y la disociación de lo ya existente ${ }^{12}$.

Anaxágoras señala varias características que hacen al nous diferente de la mezcla. Y por ello se ha estimado que debe hablarse de un dualismo ${ }^{13}$ de los principios del universo: el nous como principio intelectual y la mezcla como principio material, ambos coeternos y preexistentes. Esta postura permite ver en Anaxágoras un rompimiento con el materialismo y monismo jónicos, en tanto que existe un principio alterno como la causa del movimiento ${ }^{14}$. Al separar al agente que estaba contenido en el arjé, Anaxágoras otorgaría a la causa motriz un estatuto propio. Y si bien el nous posee características que lo hacen diferente a la mezcla, no es, propiamente, contrario a la materia, como lo expondremos más adelante. Para poder dar comienzo a esta argumentación, es relevante que, aún considerando la posición dualista, se comprenda que los dos polos que la conforman son el nous y, por el otro lado, la mezcla. Es decir, que los polos no son propiamente el nous y la materia. Por lo cual se invita a no identificar categóricamente a la mezcla con la materia, o bien, no concebir a la materia o lo material sólo como la mezcla, ya que como incluso advierte Lanza, Anaxágoras todavía no posee un concepto de materia como tal y, por lo mismo, tampoco claramente de lo inmaterial ${ }^{15}$.

11. DK 59 B 12.

12. DK 59 B 17.

13. Cfr. A. Cappelletti, La filosofía de Anaxágoras cit., 244 y A. Bernabé, Fragmentos presocráticos: de Tales a Demócrito (Alianza, Madrid, 2008) 252.

14. Es decir: "[...] requiere de una segunda causa que no esté sujeta a la mezcla, algo que suministre el empuje inicial al movimiento [...]". W. JAEGER, La teología de los primeros filósofos griegos. Trad. José Gaos (Fondo de Cultura Económica, México, 1952) 162.

15. "Anassagora definisce il vôै" $\varsigma$ in contrasto con questi $\chi \varrho \eta \mu \alpha \tau \alpha(. .$.$) . È l'unico$ 
Si bien generalmente se considera que la característica esencial del nous radica en su ser cognoscente, la diferencia más relevante para el Clazomenio es que el nous es libre de mezcla, porque es esta independencia de mixtura lo que le permite realizar su actividad: mover. He aquí una de las claves que no debemos perder de vista: el intelecto de Anaxágoras es un intelecto prioritariamente práctico ${ }^{16}$. Su actividad esencial en la cosmogonía es la generación del movimiento, causar la separación de las cosas, ordenar el cosmos. Es ello lo que radicalmente lo distingue de la mezcla: el nous es activo, porque es homogeneo ${ }^{17}$, sin mezcla, mientras que el resto de las cosas, al ser mezcladas sólo se mueven por acción y control del nous.

Sin porción de ninguna otra cosa, el nous es 'igual a sí mismo' y, por ello, absolutamente "impasible", como Aristóteles refiere ${ }^{18}$. Esta independencia es la característica que le permite al nous controlar y ordenar la mezcla, pues de lo contrario "[...] las cosas mezcladas con ella le impedirían que pudiera gobernar [...]"19.

Se deduce de lo anterior, que su poder le es propio por su ser no mezclado, que lo hace autónomo ${ }^{20}$ : libre para mover y actuar, permitiéndole, asimismo, ejercer su actividad cognoscitiva. Pues, de hecho, el conocimiento es para Anaxágoras un aspecto que le sobreviene a la actividad del nous, a su poder de movimiento ${ }^{21}$. De modo que a su función primaria o más propia, que es la eficacia sobre el mundo, se asocia su capacidad cognoscitiva.

modo in cui è possibile intuire l'immateriale a chi non ha ancora il concetto di materia”. D. LANZA, Il pensiero di Anassagora (Istituto lombardo di scienze e lettere, Milano, 1965) 269, citado en D. TorrIJOS, Anassagora, il noûs e la conoscenza, "HYPNOS" 30/1 (2013) 127-138.

16. "[...] viendo que el noûs de Anaxágoras contribuye a la aún incipiente elaboración filosófica de la noción de entendimiento, es evidente que éste nace más como entendimiento práctico que teórico". D. TORRIJOS, Anaxágoras y su recepción en Aristóteles (EDUSC, Roma, 2014) 192.

17. DK 59 B 12 .

18. Cfr. ARISTóteles, De Anima, I 405b 20.

19. DK 59 B 12.

20. Ibidem.

21. "En la filosofía de Anaxágoras el poder parece conceptualmente anterior al conocimiento mismo, hasta el punto de ser concebido éste mismo como un tipo de poder”. D. Torrijos, Anaxágoras cit., 192. 
Si bien no puede hablarse formalmente de una teoría del conocimiento en Anaxágoras, y de hecho son escasas las señales que los fragmentos nos brindan sobre el modo de conocer del nous ${ }^{22}$, cierto es que el Clazomenio no es apocado en cuanto a la afirmación de su poder cognoscitivo, otorgándole al nous universalidad y omnisciencia: “[...] tiene el conocimiento todo sobre cada cosa y el máximo poder. [...] Conoce todas las cosas mezcladas, separadas y divididas" 23 . El nous conoce la totalidad de los componentes de la mezcla, todas las cosas desde el principio, despúes de la rotación, así como en la reordenación y distribución. Su acción, su poder y conocimiento es universal, abarca todo lo mezclado: "[...] lo que iba a ser, lo que fue pero ahora no es y todo lo que ahora es y será, incluso esta rotación en la que giran ahora las estrellas, el sol y la luna, y el aire y el fuego que se están separando" ${ }^{24}$. Lo relevante es advertir que el intelecto goza de capacidad cognoscitiva porque es diferente de las cosas: no está mezclado como todas ellas ${ }^{25}$.

Con este panorama podemos recapitular señalando las características que Anaxágoras otorga al nous y que lo hacen otro que la mezcla: es homogéneo, igual a sí mismo, no tiene porciones, es activo, actúa sobre la mezcla, mueve y separa, es autónomo, tiene un poder eficiente y todo lo conoce. Son estas propiedades las que hacen del nous un intelecto que actúa y ejerce su poder en el mundo de manera trascendente, en cuanto que es distinto al resto de las cosas, esencialmente porque no presenta mezcla en su ser.

Expondré ahora el caso bruniano del intelecto como causa eficiente universal interna al mundo.

22. Torrijos elabora una revisión interesante sobre el conocimiento inteligible del nous a la luz de las noticias sobre el conocimiento sensible de Anaxágoras ofrecidas por el testimonio de Teofrastro: Cfr. D. TORRIJOS, Anaxágoras cit., capítulo IV.

23. DK 59 B 12.

24. Ibidem.

25. Torrijos compara el fragmento 12 y el De Anima III, 4 para mostrar que Aristóteles adopta el planteamiento de Anaxágoras al respecto de la necesidad de que toda facultad cognoscitiva carezca de aquello que puede conocer. Cfr. D. TorrIJOS, Anaxágoras cit., 362-365. 


\section{LA INMANENCIA DEL INTELECTO: EL CASO DE GIORDANO BRUNO}

La filosofía bruniana es uno de los intentos más importantes por ofrecer una argumentación metafísica sólida respecto de 'lo infinito', que si bien (siguiendo la tradición filosófica) es considerado un atributo propio de Dios, la infinitud, para Bruno, es ya una característica compartida con el universo. Ello es así porque Bruno comprende al cosmos como la más propia manifestación de Dios. Siendo reflejo divino, efecto de ese primer principio infinito que es todo el Ser (Dios), el universo se vuelve, a la vez, infinita totalidad ontológica. Es la expresión natural de la potencia infinita, la simplicidad óntica de Dios exteriorizada en la totalidad universal: "la esencia divina [...] desplegada a través de la infinita variedad de creaturas [...] de un modo tal que el mundo no aparezca como algo que se opone a la divina potencia, sino, antes bien, como [...] la parte visible de su perfección" 26 . De manera que el universo infinito es "[...] todo lo que puede ser [entiéndase: todo el ser posible] de un modo desarrollado, disperso y distinto. Su principio [en cambio] es único e indistinto [...]"27.

El universo es vestigio divino ${ }^{28}$, y como tal, es todo lo que puede ser pero lo es de manera temporal, a través de la generación y corrupción de las formas naturales "[...] que van y vienen, decaen y se renuevan [...]"29. Esta totalidad cambiante (el universo) es y debe ser eterna e infinita. De lo contrario se consideraría ociosa y estéril

26. M. J. Soто, Metafísica del infinito en Giordano Bruno (Cuadernos de Anuario Filosófico, Pamplona, 1997) 30.

27. Causa, BOEUC III 207. Paréntesis mío. Como es habitual, cito la obra de Bruno según volumen y página de la edición crítica, esto es, sin hacer referencia en concreto, a la numeración interna del diálogo: CEuvres complètes. De la cause, du principe et de l'un. Trad. Luc Hersant. Vol. III (Belles Lettres, Paris, 1996). Para citar esta obra en castellano: G. BRUnO, De la causa, principio y uno. Trad. Ángel Vasallo (Losada, Buenos Aires, 1941).

28. Cfr. Causa, BOEUC III 109; T. LeINKAuf, Kommentar, en BW III 322. Über die Ursache, das Prinzip und das Eine (Meiner, Hamburgo, 2007). Ver también su comentario de "universale effeto". BW III 326.

29. Causa, BOEUC III 191. 
a la eficacia divina ${ }^{30}$. La premisa bruniana que sostiene la infinitud del cosmos es la correspondencia ontológica que debe existir entre el Primer Principio y su efecto, pues "si Dios es verdaderamente infinito, ésta es la razón para que su creación, el universo, sea infinito también" 31 . La capacidad de Dios no puede verse pobremente limitada en la producción de un cosmos finito. Por ello, Bruno combatirá (hasta su muerte) la concepción cosmológica teorizada y sostenida en el sistema aristotélico-ptolemaico: la visión de un universo determinado por un límite físico, la esfera de las estrellas fijas. Más adelante retomaremos la importancia de esta temática, de la apertura bruniana hacia la infinitud espacial del cosmos, para reconocer un atisbo del planteamiento sobre la trascendencia. Pues, a pesar de ser Dios el principio y la causa del universo (que lo hace ontológicamente diverso), Bruno — como hemos indicado ya- equipara la causa a su efecto: a Dios (infinito) con el universo (infinito).

El centro de esta correspondencia Dios-cosmos se encuentra en la concepción de materia. La radicalidad del giro en la noción bruniana podríamos asemejarlo al ajuste paradigmático que implicó el cambio de localización de la Tierra en el sistema copernicano. Ya que en la filosofía de Bruno la materia abandona el lugar que la tradición platónica y aristotélica le habían otorgado: deja de ser el grado último del ser "[...] esa pura y desnuda potencia sin acto [...]"32 para situarse en su nuevo/antiguo sitio: en la categoría de principio sustancial universal ${ }^{33}$, lo que genera - al menos para la fi-

30. Cfr. Infinito, BOEUC IV 83 y 85. CEuvres complètes. De l'infini, de l'univers et des mondes. Trad. Jean-Pierre Cavaillé, Vol. IV (Belles Lettres, Paris, 2006).

31. A. Calcagno, Giordano Bruno and the logic of coincidence: unity and multiplicity in the philosophical thought of Giordano Bruno (Peter Lang, New York, 1998) 164. Para el desarrollo en extenso del tema Cfr. M. A. GRANADA, Il rifiuto della distinzione fra potentia absoluta $e$ potentia ordinata di Dio e l'affermazione dell'universo infinito in Giordano Bruno, "Rivista di storia della filosofia" 49 (1994) 495-532.

32. Causa, BOEUC III 251. "It was not, that is, the prope nibil of Aristotelian philosophy but instead, no less than the World Soul, a 'substance"”. D. KNox, Bruno: Immanence and transcendence in De la causa, principio et uno, Dialogue II, "Bruniana \& Campanelliana" XIX/2 (2013) 463-482, 474.

33. Digo que es un nuevo/antiguo sitio porque la materia bruniana es una "recolocación" y revaloración: recupera el sentido (y el lugar) de principio y sustrato que tenía en los presocráticos y que se perdió en la tradición platónico-aristotélica. La materia retoma su antiguo sitio, el sentido de los milesios, que es nuevo en contras- 
losofía bruniana-, una total transformación en la estructura paradigmática ontológica.

[...] las formas no tienen el ser sin la materia, en ésta se engendran y corrompen, surgen del seno de ésta y en él se acogen; por lo cual la materia, que permanece siempre fecunda y la misma, debe tener la prerrogativa capital de ser reconocida como el único principio sustancial, como aquello que es y permanece siendo $[\ldots]^{34}$.

La materia de Bruno es principio activo y universal, es sujeto absoluto. Ella es la sustancia única, no sólo de la totalidad natural y de cada una de las cosas, sino materia común a todo: a lo sensible y a lo inteligible ${ }^{35}$. Ello es así porque se trata, propiamente, del principio activo de racionalidad. Para comprender este sentido, debemos revisar algunos aspectos esenciales de la materia y su unidad esencial.

Como principio, la materia siempre está unificada (si no es que identificada) con el alma del mundo ${ }^{36}$. Esta anima mundi es forma universal, la única que constituye a todo el universo y que no se concibe "[...] como semejante a una forma accidental, ni como mezclada con la materia [...] sino como existente en ella, como asociada y presente a ella" ${ }^{37}$, en grado tal que no existe "[...] materia enteramente privada de forma [...]"38, del mismo modo que tampoco

te con las tradiciones filosóficas predominantes: "Vemos que todas las formas naturales se desprenden de la materia y vuelven a la materia; por lo que en realidad parece que, salvo la materia, ninguna cosa es constante, durable, eterna y digna de ser tenida por principio". Causa, BOEUC III 189.

34. Ibidem.

35. Cfr. L. Spruit, Il problema della conoscenza in Giordano Bruno (Bibliopolis, Napoli, 1988) 173. Y para este tema en Bruno: cfr. Causa, diálogo IV.

36. El alma del mundo ya no es el momento hipostático antecedente de la materia como lo es para el neoplatonismo. La relación jerárquica: Inteligencia-Alma-Materia, la ha disuelto Bruno en una fuerte unificación: Inteligencia, alma y materia conforman la unidad ontológica absoluta. Para una revisión de estos principios brunianos cfr. W. BeIERWALTES, Introducción a la edición Von der Ursache, dem Prinzip und dem Einen, P. R. Blum (ed.) (Meiner, Hamburg, 1993) y E. NAMER, Les aspects de Dieu dans la philosophie de Giordano Bruno (Felix Alcan, Paris, 1926).

37. Causa, BOEUC III 141. Cursivas mías.

38. Ibidem. 
puede existir forma alguna (sensible o inteligible) sin materia ${ }^{39}$, "[...] la materia así como la forma sustancial de cualquier cosa natural, que es el alma, son indisolubles [...]"40, en tanto que "[...] la una es causa de la definición y determinación de la otra" ${ }^{41}$. Materia y alma son principios universales eternamente unificados, co-implicados.

Constituyen la unidad sustancial única, es decir, se sitúan como la unidad ontológica absoluta porque son el principio unificado de la potencialidad y de la actualidad de todo el "ser". Ya que, como indica Bruno, no es posible que pueda hacerse todo (actualidad) "[...] sin que haya al mismo tiempo aquello que puede hacerse todo" 42 (potencialidad). Este subjetum universal de materia y alma es el "[...] acto y potencia de todo, toda presente en todo. Porque, en definitiva, bien que haya individuos innumerables, todo es uno [...]"43, todo es el mismo sujeto: materia y forma (o alma) universal. "La única materia coincide, pues, con la única forma [...] están unidas de modo inseparable la una de la otra" ${ }^{44}$, desde lo más mínimo (los átomos brunianos), hasta el máximo: el universo y los sistemas solares innumerables (que pueblan el espacio infinito), todo es, por igual, la misma sustancia material-formal: acto y potencia ontológicas en unificación.

Tanto la unidad como la diversidad de la naturaleza se constituyen a causa de este sujeto, pues la multiplicidad y variabilidad radican también en la unidad de estos principios. Es la "[...] diversidad al interno de la unidad [que] viene elaborada por un principio universal que Bruno [...] formula [...] como [...] intelecto universal" ${ }^{45}$. Este intelecto es comprendido como la "más íntima y [...] propia facultad y eficacia del alma del mundo" ${ }^{46}$. Que, como señala Dagron, ello

39. "Intelligible realities [...] retained their own identity as separate substances in combination with matter but did not exist separately from it". D. KNOX, op. cit., 476.

40. Causa, BOEUC III 185.

41. Causa, BOEUC III 141.

42. Causa, BOEUC III 169.

43. Causa, BOEUC III 253.

44. L. SpRUIT, op. cit., 173-174.

45. Ibidem, 165. Cursivas mías.

46. Causa, BOEUC III 113. 
aparta a Bruno de Plotino "una vez que propone definir el intelecto eficiente como una 'facultad' o una 'parte' del alma del mundo, no como una hipóstasis propiamente dicha" ${ }^{47}$. Este contraste permite advertir uno de los planos de la inmanencia del intelecto bruniano: la subordinación ontológica plotiniana del alma respecto del intelecto desaparece, al ser éste no ya quien la genera, sino una parte del alma misma, la más íntima. El intelecto no ocupa más el nivel hipostático anterior "[...] no está definido por su trascendencia como una realidad distinta del alma del mundo"48, así como tampoco trascendente a la realidad material, es decir, al mundo sensible, de acuerdo a los supuestos neoplatónicos, como señala $\mathrm{Knox}^{49}$. Siendo el intelecto una facultad del alma, no es ni inferior ni superior a ella. "La distinción no será más una distinción de sustancias, sino una distinción de funciones" ${ }^{50}$, indica Namer.

El intelecto será principio eficiente, causa de la diversidad porque es el que origina todas las cosas determinando "[...] a la naturaleza a producir sus especies según conviene" ${ }^{51}$. Interno al alma y, por ende, a la materia misma, es el agente del universo, el hacedor de todo lo que hay en él. Como el nous de Anaxágoras, el intelecto universal es un agente práctico. Como causa eficiente, su acción es la producción de las cosas pero, en tanto que inteligente, su producción no es mecánica. El intelecto no obra a ciegas, sino que "[...] configura, forma y entreteje la materia en órdenes tan admirables que en manera alguna pueden atribuirse al azar ni al cualquier otro principio que no tenga en sí la aptitud de diferenciar y ordenar" ${ }^{52}$. Características que, sin duda, recuerdan a lo propio del nous.

Para comprender su función, Bruno señala un símil con la actividad artística (intelecto humano). El artista, para trabajar su pro-

47. T. Dagron, Unité de l'être et dialectique: l'idée de philosophie naturelle chez Giordano Bruno (Vrin, Paris, 1999) 245.

48. Ibidem.

49. Cfr. D. KNox, op. cit., 469.

50. E. NAMER, op. cit., 49.

51. Causa, BOEUC III 113 y 115.

52. Causa, BOEUC III 115. Cursivas mías. 
ducto, concibe primero la forma que dará a la materia para poder producirla. Y, así también, lo hace el intelecto universal:

Pues todo agente que obra conforme a la norma intelectual no trata de realizar algo sino con alguna intención, la cual supone la aprehensión de alguna cosa, que no es que la forma de la cosa a producir. Por tanto, este intelecto, que tiene poder de producir todas las especies [...] preciso es que las tenga de antemano todas formalmente de algún modo, sin lo cual el agente no podría proceder a fabricarlas; de la misma manera que al escultor no le es posible ejecutar diversas estatuas antes de haber imaginado diversas formas ${ }^{53}$.

En consecuencia, se entiende que en la actividad del intelecto existen dos tipos de formas: "[...] la una, que es causa, no ya eficiente, sino aquélla por medio de la cual la eficiente actúa; la otra es [el] principio, el cual es suscitado de la materia por la [causa] eficiente" ${ }^{54}$. La forma preconcebida es pues, la intentio de su acción. El agente del universo posee de modo inteligible ya todas las formas del mundo natural ${ }^{55}$, con lo cual es capaz de producirlo todo. Son dos formas de causalidad en el eficiente: "[...] aquella que engendra las 'especies' o las 'razones' de las cosas y aquella que ejecuta" ${ }^{56}$.

Lo característico de esta producción es que es sucesiva, ininterrumpida, fecunda. El intelecto produce todo en cada detalle "[...] desde lo interior de la semilla o raíz echa y desarrolla el tronco; del interior del tronco extrae las ramas [...] del interior de éstas despliega los botones, desde dentro forma, configura y teje [...] las hojas, las flores, los frutos [...]" 57 . Por ello dice Bruno que "[...] la naturaleza lo hace todo con su materia por separación, parto y efusión según [...] lo comprendieron Anaxágoras y Demócrito [...]" ${ }^{\text {58, }}$

53. Causa, BOEUC III 119.

54. Causa, BOEUC III 121.

55. Concepción heredada de Plotino. Cfr. Enéadas V 9, 5, 19-23.

56. T. DAGRON, op. cit., 250.

57. Causa, BOEUC III 117.

58. Causa, BOEUC III 257. 
porque en Bruno, la materia es progenitora, al contener en sí al intelecto con las formas, las cuales, se conciben, se generan y se extraen de ella por medio de la acción eficiente del intelecto (como la separación clazomenia).

La ejemplaridad y total eficiencia del intelecto no tienen, en efecto, otra finalidad sino la misma producción de las cosas naturales, no ya de manera inteligible sino sensible. Bruno indica que "el fin y la causa final que la causa eficiente se propone es la perfección del universo, perfección que consiste en que en las distintas partes de la materia la totalidad de las formas tenga existencia actual" ${ }^{29}$. La finalidad del eficiente es, pues, la propia realización de la variabilidad, diversidad y abundancia del mundo natural. Se trata, por tanto, de una finalidad que está siendo permanentemente actualizada, porque la acción del intelecto es, como aquélla del nous, constante, presente y extendida a todo el universo. Transformando y produciendo la diversidad, el intelecto universal, "uno e idéntico, lo llena todo" ${ }^{60}$ : la totalidad infinita material.

Debe notarse, a partir de lo expuesto, que la acción de este eficiente no es ni tiene un efecto ajeno o diferente al mismo mundo, más aún, es el propio mundo. Tanto su eficiencia como su resultado se realizan en la propia materialidad. Como señala Mendoza, la producción y actualización de todas las formas posibles, que es la función del intelecto universal "[...] no es trascendente, por ser un atributo esencial de la materia" ${ }^{61}$. Porque el fin y la eficiencia por la cual el agente actúa, no sólo requieren de un sustrato (la materia) para realizarse (como ocurre con la actividad de cualquier artista), sino que lo propio de este agente universal, lo que lo caracteriza (y distingue del símil con el arte), es que actúa y produce dando forma a la materia pero "configurándola desde dentro" ${ }^{62}$. Por eso Bruno lo llama artifice interno ${ }^{63}$, porque

59. Causa, BOEUC III 121.

60. Causa, BOEUC III 113.

61. R. MEndoza, op. cit., 16.

62. Causa, BOEUC III 117.

63. Se comprende la naturaleza como producto del arte divino, un interno poder arquitectónico. Cfr. T. LeINKaUf, Kommentar, en BW III 346. 
el agente universal actúa como artista, pero “esculpe” desde el interior de la materia ${ }^{64}$.

En efecto, la materia tiene en su interior al alma y al intelecto. Es decir, contiene en sí la actualidad formal (alma) y toda la inteligibilidad (intelecto): la totalidad de las formas de manera inteligible y teniendo ella misma la capacidad de poder serlas todas. "La materia es, en última instancia, la fuente de la actualidad, porque en ella las formas tienen su actualidad permanente" ${ }^{65}$. Es por ello principio activo, porque posee la eficiencia absoluta del intelecto. $\mathrm{Y}$ por lo mismo es principio de racionalidad, al contener la inteligibilidad universal, en tanto que el intelecto eficiente, creador y poseedor de las especies inteligibles, habita y actúa en su interior ${ }^{66}$. En este sentido, Bruno advierte que es posible sostener "[...] la opinión de Anaxágoras, el cual quería que todo estuviese en todo; porque estando en todas las cosas el espíritu, el alma o la forma universal, de todo puede producirse todo" ${ }^{67}$. Con su presencia extendida a toda la materia, el intelecto llena la realidad infinita con su inteligibilidad y especies, configurándola, determinándola y transformándola toda, haciéndola inmensamente vasta, racional y compleja en todos sus detalles y niveles. Es una presencia universal que permite "[...] hacer todo de todo, según las palabras del profundo Anaxágoras [...]"68.

64. Knox señala que la descripción bruniana del intelecto como un artífice deriva del Demiurgo platónico. Pero indica que el calificativo de "interno" Bruno lo insertó para reafirmar la noción de que el intelecto es inmanente, en contraste con el Demiurgo que procedía de un mundo superior. Esta inmanencia es lo que distancia a su intelecto del platónico, a pesar de la cercanía de Bruno con esta tradición filosófica. D. KNOX, op. cit., 470 y 472.

65. L. SPRUIT, op. cit., 174.

66. "La Matière de Bruno [...] a donc autant de réalité que l'Intelligence et l'Ame du Monde. Ce n'est pas pour lui quelque chose d'irrationnel, d'irréel, d'inintelligible, mais au contraire un principe parfaitement intelligible et rationnel”. E. NAMER, op. cit., 70.

67. Causa, BOEUC III 135. Cfr. etiam, 147 y 149; y T. LeINKAUf, Kommentar, en BW III 363.

68. Furori, BOEUC VII 15. CEuvres complètes. Des Fureurs Héroïques, trad. PaulHenri Michel (Belles Lettres, Paris, 1999). Versión en castellano: Los Heroicos Furores, Introducción, traducción y notas Ma. Rosario González (Tecnos, Madrid, 1987). 
Se conforma así, una unidad funcional y ontológica: la unidad de la materia con el alma y con el intelecto. Es la vinculación de actualización y potencialidad absolutas en la materia, que hace del universo la plenitud ontológica, la manifestación total del ser: el efecto divino ${ }^{69}$. Por eso, en todo el proceso de generación y composición natural, desde el mínimo absoluto (el átomo bruniano) pasando por toda la naturaleza hasta el espacio infinito y los astros innumerables $^{70}$, en todo se halla "[...] la existencia de una intrínseca y absoluta estructura racional que permite los tránsitos entre los mínimos y el máximo [...]"71. Es vínculo que ata e une a la inmensa e infinita totalidad: una misma materia impregnada de inteligibilidad. Un intelecto universal como eficacia divina actuando desde el interior del mundo como absoluto poder creador inteligente, presente, activo e intrínseco a toda la materia, esto es, "[...] el infinito realizarse de la infinita potencia divina en aquella imagen viviente de Dios que es el cosmos"72.

Bajo esta óptica es que Bruno adopta, recibe y recoge la visión del clazomenio: “Anaxágoras y Empédocles, [...] estimando que la omnipotente y omniparente divinidad colma el todo, no hallaban cosa tan insignificante que no creyeran que bajo ella se encontrara oculta, según todas las razones [...]"73.

Ante la concepción de la efectividad divina así de presente y penetrante en el todo "[...] se vuelve todavía más complicado distinguir al universo como uno, ente, infinito, de un principio que, en tal

69. Ésta es la "dificultad" a la que nos introduce Bruno: los calificativos propios del ser divino los vemos aplicados por igual al universo " [...] que viene denominado como uno, ente, verdadero. [...] El ens unum no califica solo al fundamento de la realidad, sino también la realidad en cuanto totalidad". L. SPRUIT, op. cit., 178.

70. "Su modelo [el de Bruno] tenía que dotar de racionalidad a los cuerpos celestes y a sus elementos constitutivos, los átomos. Esto era [...] imposible sin introducir un agente racional capaz de iniciar y dirigir el movimiento atómico y astral para introducir orden en el cosmos". R. MENDOZA, op. cit., 12.

71. E. Schettino, The necessity of the Mininma in the Nolan philosophy, en H. GaTTI (ed.), Giordano Bruno. Philosopher of the Renaissance (Ashgate, Aldershot, 2002) 299-325, 321.

72. A. Ingegno, Cosmologia e filosofia nel pensiero di Giordano Bruno (Nuova Italia, Firenze, 1978) 78.

73. Furori, BOEUC VII 389. 
caso, trascienda al universo"74. Intentaremos atisbar en qué sentido ocurre esta trascendencia en Bruno y su equivalencia con el nous.

\section{EL INTELECTO TRASCENDENTE E INMANENTE: ANAXÁGORAS Y BRUNO}

Expondré ahora el sentido de la ambivalencia en los dos planteamientos en torno al intelecto: si bien Anaxágoras señala la diferencia del intelecto con respecto a la mezcla material, existen dudas respecto de su trascendencia en cuanto que existe un resquicio de materialidad en el nous. Por su parte, Bruno, afirmando la inmanencia del intelecto en la materia, mantiene el señalamiento de su ser trascendente con respecto al mundo.

A pesar de las cualidades del nous, no puede afirmarse con rotundidad su inmaterialidad. Se ha discutido ampliamente sobre ello debido a que Anaxágoras lo caracteriza como "la más sutil y pura de todas las cosas [...]"75. Asimismo, expresa que "la Mente, que siempre es, está ciertamente ahora incluso donde están también todas las demás cosas, en la masa circundante y en las cosas que han sido unidas o separadas"76. Esta descipción sugeriría que el nous está presente en la materia y que es extenso ${ }^{77}$.

Drozdek $^{78}$ y Guthrie ${ }^{79}$ refieren que Anaxágoras no contaba con la terminología adecuada para expresar la inmaterialidad. Si bien esta tesis no está descontextualizada, lo cierto es que el nous "no está

74. L. SPRUTT, op. cit., 176.

75. DK 59 B 12.

76. DK 59 B 14.

77. Cfr. A. DrozdeK, Anaxagoras' cosmic mind, "Estudios clásicos” 127 (2005) 23-36, 26.

78. Drozdek advierte que la realidad intangible y la mención de un orden no corpóreo aparecerá hasta Platón. Así, no es posible encontrar en Anaxágoras precisión en su exposición del nous: "Is Mind an immaterial being? We should not expect from Anaxagoras a clear statement in this matter since requisite terminology did not exist yet. We have to wait until Plato to read about immaterial $(\alpha \sigma \omega \mu \alpha \tau \alpha)$ idea (Sph. 246b) and immaterial order (Phlb. 64b)". Ibidem.

79. Guthrie sostiene que la falta de términos adecuados impide a Anaxágoras referir la inmaterialidad del nous y, por ello, sólo puede expresarlo señalando su independencia de la mezcla, es decir, en modo negativo: describiéndolo como no-mezclado. Cfr. W.K.C. GuTHRIE, op. cit., 286-287. 
concebido de un modo totalmente abstracto" ${ }^{80}$, no es un principio inmaterial sin más. Sería necio desestimar el hecho de que su ser es diferente al resto de las cosas y ello, de manera principal, porque el nous "es al mismo tiempo un principio de orden intelectual" 11 . De manera que es un agente diferente, más no ajeno a la materia, posee características muy peculiares que lo hacen — por así decir-, de una materia de distinto rango: materia sutil (no mezclada) ${ }^{82}$. Ya que "aun siendo extenso, es pensante" ${ }^{83}$.

Por eso indica Cappelletti que la naturaleza del nous es ser al mismo tiempo materia y espíritu. Pues siendo materia, no es sólo materia; e imprimiendo movimiento, no sólo es una causa mecánica. La mezcla es sólo extensión. Pero el nous, siendo extenso y material, es principio de racionalidad ${ }^{84}$. Conoce (actividad espiritual), pero también mueve (actividad mecánica). Siendo extenso es autónomo: aclara, ordena, diferencia, separa. Por eso Ramnoux señala que la de Anaxágoras "es una filosofía que promueve un ser aparte que no es una trascendencia" ${ }^{85}$. Sin embargo, quizá habría que especificar esto diciendo que en Anaxágoras no hay una trascendencia total del nous.

Como materia sutil, el nous sobrepasa ciertas características de la materia (la trasciende), en tanto que es enteramente ajeno a las condiciones materiales en mezcla. Puede decirse que está separado por estar fuera del campo de la mezcolanza material, pues desde siempre está exento de la confusión de la materia, aun con su materialidad. Es así un principio intelectual (trascendente) con presencia material (inmanente). Se concluiría entonces, junto con Cappelletti, que la relación del nous con la materia es una relación de oposición al mismo tiempo que es una correlación ${ }^{86}$ : pues el nous es pensamiento, lo cual, lo hace no sólo opuesto sino trascendente a la materia; pero,

80. J. MARTin. Fragmentos de Anaxágoras. Traducción y Estudio preliminar (Aguilar, Buenos Aires, 1962) 22.

81. Ibidem, 26.

82. Cfr. A. DrozDEK, op. cit., 26.

83. A. CAPpelletti, La filosofía cit., 268.

84. Cfr. Ibidem, 248-249.

85. Citado en A. Cappelletti, Ibidem, 249.

86. Ibidem, 255. 
a la vez, el nous es sustancia extensa, por lo que está en íntima composición y relación con la materia ${ }^{87}$.

En Bruno encontramos explícitamente el señalamiento de que el inmanente intelecto universal es, a la vez, trascendente: "[...] verdadera causa eficiente, no sólo intrínseca, sino también extrínseca, de todas las cosas naturales" ${ }^{8}$. Porque el intelecto produce desde el interior de la materia, pero es 'artífice', es decir, es causa: su naturaleza óntica es extrínseca. El intelecto no forma parte constitutiva de las cosas. Como el sutil nous que actúa sobre la mezcla material sin confundirse nunca con ella, el ser del intelecto "no es el de las cosas engendradas y corruptibles, bien que actúe sobre ellas" 89 .

Respecto al ser, cuya condición es inamovible, el intelecto es una causa (extrínseca); pero en cuanto a la operación, que es dinámica, el intelecto es principio (intrínseco) ${ }^{90}$. El formador universal es causa desde el punto de vista del ser, pero es principio desde el punto de vista de su actividad, como lo expresa Bruno: "es causa extrínseca porque su ser es distinto de la sustancia y esencia de los efectos [...] es causa intrínseca en cuanto al acto de su operación"91. Aun siendo el principio inmanentemente que hace a todas las cosas (y de hecho permanece en todas), el intelecto no es ninguna de ellas, su ser estructurante es otro que lo producido. Como el nous, el intelecto no es de la misma naturaleza que el resto de las cosas, sino que las trasciende; e igual que aquél, actúa y no se aparta de la materia (inmanencia). Así, 'causa' y 'principio' denotan los dos modos en que las cosas se relacionan con el intelecto, indica Knox. Siendo por él

87. En los presocráticos la oscilación entre trascendencia e inmanencia del principio no es exclusiva de Anaxágoras. Sus planteamientos hablan repetidamente de principios materiales concebidos con características metafísicas, por ser universales, eternos, incorruptibles, imperecederos, etc. Son principios materiales trascendentes. Para los presocráticos, la naturaleza es el "[...] horizonte que posibilita toda otra pregunta, sea sobre lo cósmico, lo humano o lo divino. [...] aquello que le envuelve [al hombre] al tiempo que le sobrepasa". G. FernádeZ, Heráclito. Naturaleza y Complejidad (Thémata/Plaza y Valdés, Sevilla/Madrid, 2010) 68.

88. Causa, BOEUC III 119.

89. Ibidem.

90. Cfr. S. MANCINI, La sfera infinita. Identità e differenza nel pensiero di Giordano Bruno (Mimesis, Milano, 2000) 113.

91. Causa, BOEUC III 119. 
producidas, necesariamente se diferencian porque es su causa externa. Pero es principio interno porque cada una se mantiene según el orden derivado de él ${ }^{92}$.

Así, aun con la inmersión de la actividad divina en el cosmos y con la concepción del univeso como su manifestación, Bruno mantiene una distinción metafísica entre Dios y el cosmos. Pues “[...] sin localizar a Dios fuera del mundo [...] Dios, sin embargo, no es absorbido por el universo o por su estructura" ${ }^{93}$. Al contrario, es su presencia en el mismo lo que confiere orden, estructura, inteligibilidad. Con el intelecto presente en toda la materia "[...] la unidad divina invade y sostiene toda la realidad" 94 , generando una vinculación universal que íntrínsecamente hace de todas las cosas una sola y la misma, pues ninguna puede estar fuera de Dios y de su configuración. Es, como señala Ingegno, una unión que consiste, recíprocamente, en la presencia y ausencia divina en todas las cosas: "[...] presente en cada cosa pero no circunscrito a eso, como participante en todo sin que nada pudiera agotar su naturaleza y poder" ${ }^{95}$. Planteamiento muy similar al que encontramos en Anaxágoras, un intelecto presente en toda la masa, pero en nada semejante a las cosas mezcladas. A este respecto, el mismo Bruno expresa:

No deja Anaxágoras de poner a contribución a la naturaleza porque así en ella [inmanente] como fuera y quizá por encima de ella [trascendente] presuma conocer un intelecto, el mismo que por Sócrates, Platón, Hermes Trismegisto y nuestros teólogos es llamado Dios ${ }^{96}$.

En ambas posturas se encuentra, así, la coincidencia y la distinción entre el intelecto y el mundo. Pero en Bruno esta reciprocidad entre inmanencia y trascendencia puede verse intensificada con el planteamiento de la infinitud: pues si Dios está presente en todo y en cada

92. Cfr. D. KNox, op. cit., 480-481; Causa, BOEUC III 109 y 113.

93. L. SpRUIT, op. cit., 182.

94. Ibidem, 180.

95. A. INGEGNO, op. cit., 61.

96. Causa, BOEUC III 201. Paréntesis mío. 
parte del mundo infinito, su ser es física, metafísica y cognoscitivamente inagotable. El divino artífice, en su infinito manifestarse en un cosmos pleno y sin límite, no sólo es inagotable espacialmente, sino inalcanzable para el conocimiento humano. Las esculturas de Apeles "podemos verlas todas y examinarlas en todos sus detalles, más no así el grande e infinito efecto de la potencia divina" ${ }^{97}$. La inmersión en el cosmos infinito, no agota el ser de Dios. Garantiza la estructura del universo, pero no se identifica con ello - advierte Spruit-, pues Dios no se limita a su función en la realidad: "como principio estructurante, Dios se mantiene distinto a aquello que une" 98 . Por eso, "la unidad física del mundo puede ser fundada solamente por la distinción metafísica entre Dios y el mundo"99. Así, Bruno distingue (abstractamente) al intelecto divino del intelecto universal ${ }^{100}$, en cuanto que éste es reflejo de aquél, es su presencia eficiente en el cosmos, pues "el mundo es un simulacro y una imagen de una unidad superior" ${ }^{101}$. Como señala Leinkauf, el intelecto universal sería la causa eficiente directa y el divino, la causa remota actuando en el universo a través de aquél ${ }^{102}$.

\section{Conclusiones}

Bruno considera al intelecto universal como la divinidad hacedora inmanente al mundo. Sin embargo, en Anaxágoras nos hallamos ante una incertidumbre, ya que en realidad él nunca se refiere al nous como lo divino, ni lo llama Dios. Como advierte Waterfield "[...] parece menos inclinado que algunos de sus predecesores para describir, incluso a su mente cosmogónica, como 'dios' ${ }^{103}$. Guthrie

97. Causa, BOEUC III 107.

98. L. SPRUIT, op. cit., 185.

99. Ibidem.

100. Cfr. Causa, BOEUC III 117 y 119; L. SPRUIT, «intelletto», voz en E. CANONE, G. ERNST (eds.) Enciclopedia Bruniana y Campanelliana, vol. I (Pisa-Roma, 2006).

101. L. SPRUIT, op. cit., 180.

102. Cfr. T. LeINKaUf, Kommentar, en BW III 353; Causa, BOEUC III 121.

103. "[...] he seems less inclined than some of his predecessors to describe even his cosmogonic mind as 'god'." R. WATERFIELD, The first philosophers. The presocratics and the sophists (Oxford University Press, New York, 2000) 116. 
señala que "es imposible que Anaxágoras no lo haya considerado como algo divino"104. Torrijos advierte que cuando Anaxágoras se refiere al nous, lo hace sin anteponer un artículo, lo cual, indica, se estilaba para nombrar a las personas y de manera particular los nombres de los dioses ${ }^{105}$. Sin embargo, con todas sus características diferentes y "a pesar del supremo poder el nous no es abiertamente una divinidad" 106 . Este inexistente reconocimiento explícito de la divinidad del nous por parte de Anaxágoras, es similar a su no explícita afirmación de su ser inmaterial.

Ello puede considerarse una característica propia de la tradición presocrática donde los aspectos de la realidad no se conciben diferenciados. La naturaleza no está escindida entre lo activo y lo pasivo; lo físico y lo metafísico; lo material y lo inmaterial; lo trascendente y lo inmanente; lo divino y lo mundano ${ }^{107}$. Igualmente la filosofía bruniana es una invitación a reconocer la relación, coincidencia y complementariedad entre realidades contrarias ${ }^{108}$.

Esta condición simultánea de la trascendencia-inmanencia del intelecto es una postura que, por ser ambivalente, podría parecernos insensata. Sin embargo, notamos que Bruno no busca suprimir esta ambivalencia. Al contrario, la afirma y sostiene. Tampoco parece ser un problema para Anaxágoras: el intelecto es sutil y se extiende por doquier, a la vez que es lo único distinto y que todo lo conoce.

Esta "contradicción" en ambos intelectos permite advertir que la inteligencia divina presente en el mundo se nos hace evidente por su actividad, dinámica y fuerza, es decir, por la abundancia, es-

104. W.K.C. GUTHRIE, op. cit., 289.

105. Cfr. D. Torrijos, Anassagora cit., 133. Así, Torrijos sostiene que el nous es un intelecto personificado. Cfr. D. TorRIJOS, Anaxágoras cit. 152-172.

106. D. SedleY, Creationism and its critics in Antiquity (University of California Press, Berkeley, 2007) 25.

107. "[...] es elocuente el hecho de que las cuestiones fundamentales que han entretejido la filosofía occidental (Naturaleza, Razón, Hombre, Dios, etc.) se encuentren en los presocráticos reunidas como elementos de una misma sospecha [...]". G. FERNÁNDEZ, op. cit., 73.

108. "Quien quiera conocer los más importantes secretos de la naturaleza contemple y considere en torno a lo mínimo y lo máximo de lo contrarios y opuestos. Magia profunda es la de saber extraer el contrario, luego de haber hallado el punto de unión”. Causa, BOEUC III 315. 
plendor, inmensidad y complejidad de la naturaleza (el nous puede percibirse acaso sólo por el movimiento y orden que ha generado ${ }^{109}$ ). Pero, aun en todo ello, el ser de esa inteligencia universal permanece completamente fuera de nuestra vista ${ }^{110}$, totalmente inaccesible. La estructura inteligente del universo nos es evidente, pero, a la vez, nos es descomunalmente inasequible.

En conclusión, a la luz del contexto ofrecido por Anaxágoras y Bruno, es posible atisbar la razón de por qué la divinidad como causa inteligente eficiente no puede concebirse como algo completamente trascendente u otro. La inteligencia del universo si bien es por sí distinta, está inmersa en el mundo. Es tan trascendente como inmanente, pues una inteligencia divina ajena y en total trascendencia sería tan inconcebible como una en inmanencia cabal y en absoluta indistinción con el mundo ${ }^{111}$.

109. Cfr. D. Torrijos, Anassagora cit., 136.

110. Cfr. P. H. MiCHeL, The cosmology of Giordano Bruno, Trad. R.E.W. Maddison (New York Cornell University Press, Ithaca, 1973) 89.

111. Este estudio forma parte del proyecto de investigación posdoctoral (2014-2016) que, con el auspicio del CONACyT de México, he desarrollado en la Universidad de Navarra. Mi agradecimiento especial para María Jesús Soto-Bruna por la orientación, afabilidad y acogida que me ha brindado. A Iñigo Sánchez por su lectura siempre aguda y sosegada; y a Mary Carmen García, por compartirme generosamente su saber y palabras. 
